\title{
Physicochemical sensitivities of tropical peat to electrokinetic environment
}

\begin{abstract}
Tropical peat is unconsolidated superficial deposits with high non-crystalline colloid (humus) content, constituting the subsurface of wetland systems. Laboratory experiments were carried out on a very slightly decomposed fibric and a highly decomposed amorphous, undisturbed tropical peat soils, to determine the physicochemical effects on the peats due to electrokinetic (EK) treatment in terms of mechanisms and resulting effects in the presence of peat water. The different specimens were treated for 3, 6, 12, and 20-day periods. A constant electrical potential of $40 \mathrm{~V}$ was applied across the specimens. The untreated and treated specimens were tested for liquid limit (LL), undrained shear strength (Su), water content (WC), zeta potential (¥æ), pH, and cation exchange capacity (CEC). The peat water flew from anode to cathode because of the negative charges on the humus. In the vicinity of the anode, the CEC and $¥ \mathfrak{x}$ of the specimens decreased, and the Su and LL of the specimens increased because of the acidic conditions, while alkaline conditions at the cathode had an opposite effect. The sensitivity of the amorphous peat to the EK environment was higher than the sensitivity of the fibric peat to the EK environment because of larger quantities of the colloids and quality of the charges. The acid/base distributions in EK soil processing influenced the soil surface charges, which were fully $\mathrm{pH}$-dependent, resulting in the variations of the CEC and ¥æ. The $¥ \mathfrak{x}$ variations caused thinning and expanding of the diffuse double layer around the humus particles, and were linked to the flocculation and dispersion of the particles, and subsequently affected the LL and Su of the specimens. The study was found its significance in that it confirmed the relationship between the degree of peat decomposition and the peat sensitivity to the EK treatment.
\end{abstract}

